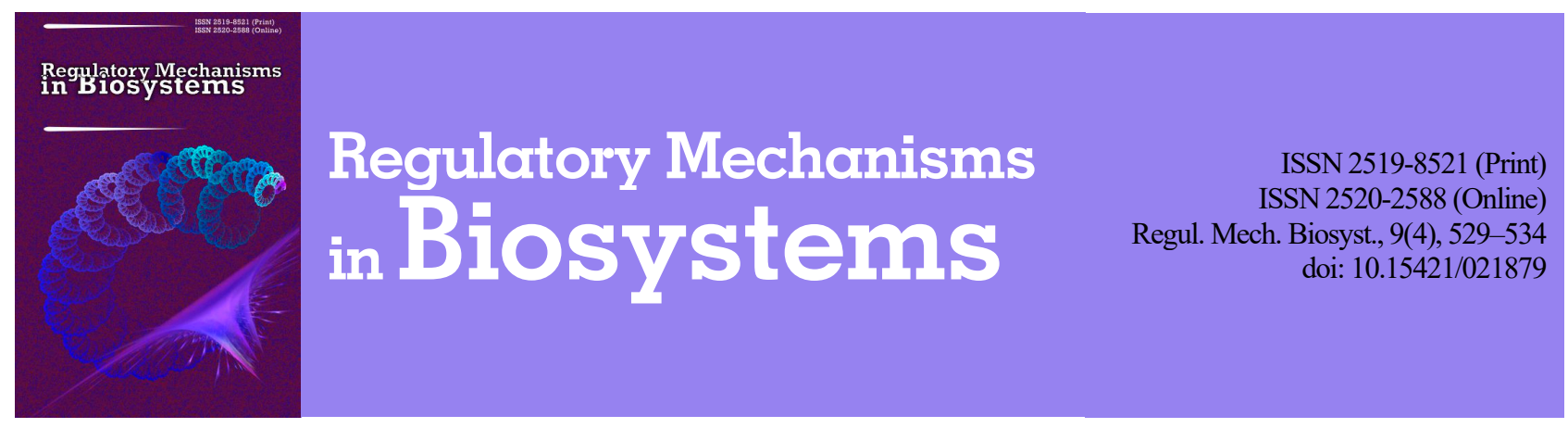

\title{
Calcium-binding protein, S100b, in the blood as a biochemical marker of the neurological state of men in warzones
}

\author{
D. V. Muraviova, M. R. Buniatov, G. A. Ushakova \\ Oles Honchar Dnipro National University, Dnipro, Ukraine
}

Article info

Received 05.10.2018 Received in revised form 08.11 .2018 Accepted 12.11.2018

Oles Honchar Dnipro National University, Gagarin av., 72, Dnipro, 49010, Ukraine. Tel.: +38-066-309-13-86. E-mail: ushakova_g@ukr.ne

\begin{abstract}
Muraviova, D. V., Buniatov, M. R., \& Ushakova, G. A. (2018). Calcium-binding protein, S100b, in the blood as a biochemical marker of the neurological state of men in warzones. Regulatory Mechanisms in Biosystems, 9(4), 529-534. doi:10.15421/021879
\end{abstract}

Acute and chronic stress are two of the most challenging issues faced by men situated in warzones. According to the main concept of G. Selye, stress response is the most important link during the adaptation of an organism to environmental factors. However, excessively intense or prolonged exposure to stress creates the threat of sustained homeostasis disorder. At present, the primary indicators in clinical studies are the general biochemical parameters of blood - alanine aminotransferase, aspartate aminotransferase, bilirubin, creatine, urea, total protein, and glucose levels. But these indicators are not classical markers for determining the state of the nervous system itself and cannot reflect a patient's mental state. In this regard, we tested for a different biomarker; we made an attempt to determine the neurospecific S100b protein in the blood serum by analyzing the correlation between classical and specific methods for diagnosing the state of the nervous system. For this study, blood was collected from 20 patients aged 25 to 45 years old. Participants were divided into two groups: one group of provisionally healthy men and another group of patients who were admitted to the Department of Neurology of the I. Mechnikov Regional Clinical Hospital after military operations (from the territory of the ATU). The standard test kits of PrAT Reagent Company (Dnipro) were used to assess biochemical indicators in accordance with the given instruction in the supplier's protocol. The activity of each of alanine aminotransferase, aspartate aminotransferase, direct and total bilirubin content, creatine, urea, total protein levels, and astrocytespecific protein S100b was examined. The level of alanine aminotransferase in the men from the warzone was $23.9 \pm 3.9 \mu \mathrm{mol} / \mathrm{l}$, compared with the healthy men $-31.2 \pm 0.7 \mu \mathrm{mol} / \mathrm{l}$. The level of aspartate aminotransferase in the group of men at the neurological department was similar to that in the healthy group. The content of direct bilirubin in the patients at the neurological department increased by $28.0 \%$, compared with the healthy men. The concentration of creatinine, total protein, urea, and glucose levels did not significantly change, compared with healthy volunteers and were in the range of the standard reference data. The content of astrocytespecific protein, $\mathrm{S} 100 \mathrm{~b}$, in the blood of the patients was $0.011 \mu \mathrm{g} / \mathrm{ml}, 36.0 \%$ more than in the conditionally healthy men $0.007 \mu \mathrm{g} / \mathrm{ml}$. Prolonged stress could, therefore, induce profound changes in blood brain barrier and registration of neurospecific protein in the blood of men in warzones. These changes could become chronic if or when these men develop other social and economic problems that can be monitored with the specific marker for S100b.

Keywords: stress; aminotransferases; bilirubin; creatinine; urea; total protein; glucose

\section{Introduction}

The first-ever metabolic vital signs are classic values of biochemical blood tests, among which are parameters of total protein, glucose, activity of aminotransaminases, and end products of metabolism, namely, bilirubin, creatinine, and urea. The activity of two of the main liver enzymes, alanine aminotransferase (ALT, CF 2.6.1.2) and aspartate aminotransferase (AST, KF 2.6.1.1) are markers of the functional state of this organ (Zhang et al., 2015; Ferrannini et al., 2017), which is key to ensuring the metabolism of blood proteins. Substances that provide gluconeogenesis are formed as a result of the metabolism of aspartate aminotransferase. Chronic stress can lead to the release of excess concentrations of cortisol in the blood, which suppresses the enzymes of gluconeogenesis, enhancing the effect of adrenaline and glucagon on the liver and stimulating proteolysis in the muscles. Aminotransferases catalyze the transamination reactions between amino and $\alpha$-ketoacids, thus taking part in the synthesis and degradation of cellular proteins. The activity of aminotransferases is insignificant in the blood of healthy people. Under standard conditions, the highest activity of aspartate aminotransferase occurs in the liver, nervous tissue, skeletal muscle, and myocardium. Alanine aminotransferase is also present in many organs, with the highest activity determined in the liver, pancreas, skeletal muscle, myo- cardium, and kidneys. An increase in the activity of these aminotransferases is observed during pathological processes in which the corresponding organs are involved (Sookoian et al., 2016).

The splitting of proteins containing heme (hemoglobin, myoglobin, and cytochrome) ensures the flow of all aerobic processes in organs and tissues, which leads to the production of an intermediate metabolite bilirubin. In small physiological doses, bilirubin acts as a natural antioxidant that inhibits the development of oxidative stress in various pathologies (Oda \& Aizawa, 2013; Haeusler, 2016; Nano et al., 2016). However, if the physiological concentration is exceeded, it becomes toxic, sparking the development of jaundice and disorders of the liver and other organs. Creatinine, formed from creatine phosphate, which is involved in the energy supply of muscle and other tissues of the human body, is also one of the terminal metabolites of amino acid-protein metabolism. Creatine phosphate is a macroergic compound that is used for rapid ATP resynthesis during muscle activity. In the cells of the nerve tissue, creatine phosphate maintains the vitality of the cells that lack oxygen. The concentration of creatinine in the blood is the primary indicator of impaired muscle tissue, brain, and filtration capacity of the kidneys (Oda \& Aizawa, 2013).

Urea is the ultimate metabolic protein and is utilized in combination with urine. This is one of the main components of the residual nitrogen of blood, accounting for about $50.0 \%$. 
The basic biochemical parameters of blood that characterize the general metabolism have a potential clinical benefit in diagnostics, prognosis, and therapeutic decision-making. They can be used to find out the pathophysiology of secondary trauma (Wang et al., 2018). However, these indicators are not classical markers for determining the state of the nervous system and cannot reflect the mental state of a patient. If significant damage is inflicted upon organs and tissues, a probable change in the features of the basic biochemical parameters of blood is observed. On the other hand, it is very difficult to determine any change in feature with minor injuries or at the initial stage of the development of the neurological state. Therefore, monitoring the state of the nervous system in today's diagnostics requires a specific biochemical marker that could indicate any form of damage to the central nervous system, irrespective of the severity of the damage.

Currently, the calcium-binding protein, $\mathrm{S} 100 \mathrm{~b}$ is used as a marker for injuries in craniocerebral traumas and infections (Di Battista, 2018). It was showed that, under conditions of experimental chronic hepatitis, the excessive elevation of the level of S-100b occurs in all parts of the brain of a rat. This phenomenon is accompanied by a deterioration in locomotor and orientational search activity of animals, increasing their susceptibility to stress (Ushakova et al., 2011). Also, S100b is a sensitive biomarker for assessing the integrity of the blood-brain barrier (BBB) (Li et al., 2014; Golmohammadi et al., 2018).

$\mathrm{S} 100 \mathrm{~b}$ is a representative of the $\mathrm{S} 100 \mathrm{Ca}^{2+}$-containing protein superfamily and is an acidic protein with a molecular weight of $21 \mathrm{kDa}$. It exists in the form of a homodimer consisting of two $\beta$ subunits. It can be secreted by astrocytes, glial cells, and the Schwann cells. Astrocytes and glial cells produce S100b in a complex system that involves changes in the intracellular $\mathrm{Ca}^{2+}$-concentration. S100b can accumulate in the intercellular space and enter the bloodstream and cerebrospinal fluid as a result of its secretion or release from damaged cells. This protein is involved in the $\mathrm{Ca}^{2+}$-dependent regulation of various intracellular processes, such as phosphorylation of proteins, enzyme activity, cell proliferation and differentiation, cytoskeleton component dynamics, structural organization of membranes, intracellular $\mathrm{Ca}^{2+}$-homeostasis, inflammation, and protection against oxidative cell damage. Intracellular S100b regulates the dynamics of the cytoskeleton through the disorganization of the tubulin of the filaments, the protein of the type III intermediate filament, and the binding of fibrillary proteins, such as the capping protein of actin (CapZ) or inhibition of the phosphorylation of glial fibrillary acidic protein (GFAP) by stimulation with cyclic adenosine monophosphate (tsAMP) or calcium/calmodulin. S100b interacts with the cytoplasmic domain of myelin-associated glycoproteins and inhibits its phosphorylation with protein kinase. In the cell, the cadmium-binding protein interacts with a relatively large number of signal proteins, thus regulating their functions.

S100b is considered the most specific for neural tissue and reacts unidirectionally in the form of an increase in its level in response to mechanical, hypoxic, ischemic, biochemical, and other neurotoxic factors (Koh \& Lee, 2014). The role of S100b protein as a marker of brain tissue damage was demonstrated initially in the study of liquor disease. High concentrations of $\mathrm{S} 100 \mathrm{~b}$ were later detected in brain injuries, brain tumors, neurodegenerative diseases, stroke, meningitis, encephalitis, perinatal asphyxiation (the level of S100b at birth and in the first 2 to 3 days of life is one of the criteria for the prediction of adaptation in preterm and assessing the severity of damage to the central nervous system), and others. In addition, an elevated serum S100b level was found during cardiac arrest, after cardiac reanimation, in cardiac surgery with cardiopulmonary bypass. Thus, this astrocyte-specific protein, S100b, is currently considered one of the nodal molecular components of complex intracellular systems that provide functional homeostasis of the brain cells by combining and integrating various calcium-dependent metabolic processes (one of the processes is the activation of creatine kinase) (Woodbury-Fariña, 2014). The contents of S100b could, hence, act as an indicator of the correlation between the classical and specific methods for diagnosing the state of the nervous system.

The problem of stress is still of paramount importance today (Gianaros \& Wager, 2015; Fox et al., 2018). Stress reaction is the most important link during the adaptation of an organism to environmental factors (Buckner et al., 2017). But recently, the strength and number of stressful situations that can affect the condition of tissues and organs have increased (Ginty et al., 2017; Kraynak et al., 2018). A spasm of the vessels, stomach, and pancreas is observed in the case of excessively intense or inadequately long-term exposure to stress factors (Kornicka et al., 2018; Tahtaci et al., 2018). Due to the high frequency of stress and an increase in its duration, these disorders increase their effect and stability, resulting in hyperglycemia (Perez de la Hoz et al., 2018). In turn, an increase in insulin concentration is observed in chronic stress. Hyperinsulinemia, as a compensatory response to insulin resistance, increases the activity of the sympathetic nervous system, which further enhances stress-response, and has a negative impact on the course and prognosis of cardiovascular diseases (Oppenheimer \& Cechetto, 2016; Brindle et al., 2017; Carroll et al., 2017).

The close relationship between organs and systems of the organism leads to violations, which, having fallen into a vicious circle, attract even more violations to it. The daily stress-induced changes to glucose levels and hyperglycemia causes excessive glycation and inactivation of antioxidants. The depletion of the antioxidant enzyme systems contributes to the development and progression of the complications of type 2 diabetes (Siddiqui et al., 2015; Gonzalez et al., 2018; Yaribeygi et al., 2018). A large number of metabolic mechanisms are activated against the background of hyperglycemia, the result of which is the formation of the active forms of oxygen and oxidative stress.

All that said, the purpose of this work is to analyze the ratio of the indices of the general biochemical analysis of blood total metabolites (total protein and glucose), key enzymes of protein metabolism (alanine aminotransferase and aspartate aminotransferase), end metabolites (direct and total bilirubin, creatinine, and urea), and astrocyte-specific protein, $\mathrm{S} 100 \mathrm{~b}$, in the blood of men stationed for a long time in the wartorn territory of the ATU and admitted to the Department of Neurology of the I. Mechnikov Regional Clinical Hospital after military operations.

\section{Material and methods}

We selected 20 men aged 25 to 45 years old for our study. Blood was drawn from the men on an empty stomach in the morning. The men were divided into two groups: a group of conditionally healthy men and a group of men from the warzone admitted to the Department of Neurology of the I. Mechnikov Regional Clinical Hospital after military operations (from the war-torn territory of the ATO).

The study of the general metabolism was conducted at the base of clinical trials at the I. I. Mechnikov Dnipropetrovsk Regional Clinical Hospital (The authors express their sincere gratitude to the manager of the clinical and diagnostic laboratory E. V. Philippova for her cooperation). The general biochemical analysis of blood was performed with standard spectrophotometric methods using the test kits of PrAT Reagent (Dnipro), according to the manufacturer's instructions for use of the kits and the protocol for the measurement of all indicators.

The total protein level was determined using a biuret reaction (Code: BP 00.5.03), in which the proteins reacted in an alkaline medium with copper tartrate (II) to form compounds of purple colouration (biuret reaction). The concentration of glucose was determined using the glucose oxidase method (PK 24.10.06), in which glucose, in the presence of glucose oxidase enzyme, is oxidized to gluconic acid and hydrogen peroxide. The latter, under the influence of peroxidase, reacts with phenol and aminophenazone to form a coloured quinonine, which is determined photometrically.

The activity of each of aspartate aminotransferase and alanine aminotransferase enzymes was determined using the Rietman-Frenkel method (AF 002-01 and AF 001-01). The principle of the method is that aspartate transferase catalyzes the reaction between L-aspartate and 2-oxoglutarate to produce L-glutamate and oxaloacetate. This definition is based on the measurement of the optical density of the hydrazones of 2-oxoglutaric and pyruvic acids in alkaline media. The hydrazone of pyruvic acid, which occurs during the spontaneous decarboxylation of oxaloacetate, has a higher optical density. Alanine aminotransferase catalyzes the reaction between L-alanine and 2-oxoglutarate, resulting in their conversion to L-glutamate and pyruvic acid salt. 
The content of direct and total bilirubin was determined by the Jedrashik-Klechhorn-Grof method (BP 002-03), which is based on the fact that diazophenylsulfonic acid is formed during the interaction between sulfanilic acid and sodium nitrate, producing a pinkish violet colouration of the blood serum and direct bilirubin. The intensity of the colour is determined by the amount of direct bilirubin. When added to the blood serum of a caffeine reagent, indirect bilirubin is converted into a direct bilirubin and is quantitatively determined by a diazo-reactive. The concentration of total bilirubin in serum is determined by the intensity of the colouration.

The concentration of creatinine is determined by means of the method of deproteinization of Jaffe-Popper (BH 018-04), which is based on the effects of trichloroacetic acid which precipitates proteins and pseudo creatinine chromogens. Creatinine picrate is formed as a result of the interaction of picric acid with creatinine in alkaline medium. The intensity of the colour is proportional to the concentration of creatinine.

To determine the level of urea, an enzymatic (urease) method ( $\mathrm{BH}$ 023.1-04) was used, in which urea is hydrolyzed under the action of urease to form ammonia and carbon dioxide. Nitroprusid in an alkaline medium catalyzes the reaction of ammonia with salicylate and sodium hypochlorite. The size of the absorption of the analyzed samples determines the content of urea.

The content of S100b protein in serum was determined by direct solid-phase enzyme-linked immunosorbent assay using primary monospecific polyclonal antibodies against $\mathrm{S100b}$, secondary anti-rabbit antibodies labeled with horseradish peroxidase, and purified protein $\mathrm{S} 100 \mathrm{~b}$ as a standard. All reagents were purchased from Sigma (USA). Measurements of the results were taken at a wavelength of $492 \mathrm{~nm}$ with an Anthos 2010 ELISA reader (Finland).

The statistical processing of the results was performed using the StatWin program via a ANOVA. The results were considered significant at $\mathrm{P}<0.05$.

\section{Results}

According to the general biochemical analysis of the blood, the total protein in the serum of the men from the warzone admitted to the neurology department was $73.4 \pm 1.1 \mathrm{~g} / \mathrm{l}$, which was not significantly different from that of the group of conditionally healthy men (Fig. 1). The reference data for the total protein level is $66.0-87.0 \mathrm{~g} / \mathrm{l}$.
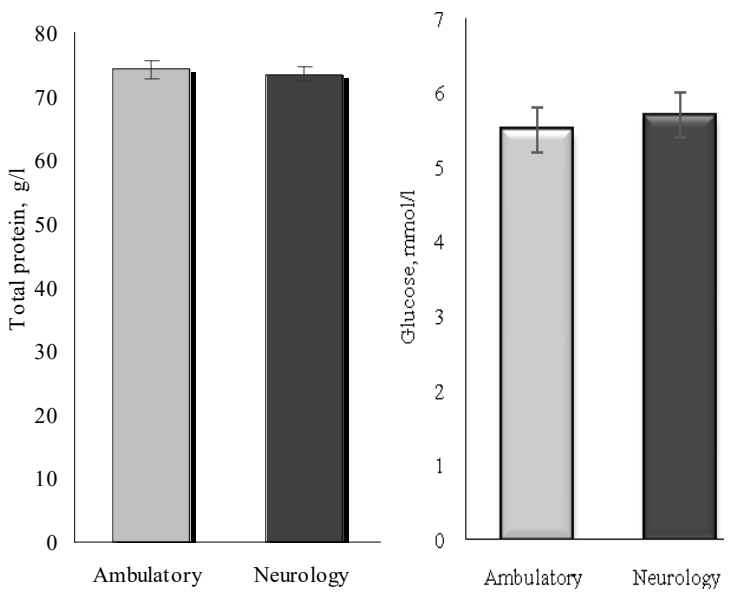

Fig. 1. The level of total protein and glucose in the blood serum of conditionally healthy men and patients at the neurology department:

$$
\mathrm{x} \pm \mathrm{SE}, \mathrm{n}=10
$$

The level of glucose of the military men from the war-torn territory of the ATU was within the range of the reference norm, $5.1-5.7 \mathrm{mmol} / \mathrm{l}$ on average (Fig. 1). The activity of aminotransferases, alanine aminotransferase and aspartate aminotransferase, in the men who donated blood for analysis at the ambulatory and neurology departments was examined. In the blood serum of the men at the Department of Neurology, the activity of alanine aminotransferase was $23.9 \pm 3.9 \mu \mathrm{mol} / \mathrm{l}$ (Fig. 2), compared with that of the conditionally healthy men (31.2 \pm
$0.7 \mu \mathrm{mol} / \mathrm{l}$ with a standard reference point of $42.0 \mu \mathrm{mol} / \mathrm{l})$. This indicator decreased significantly, by $24.0 \%$, compared with the conditionally healthy men. Aspartate aminotransferase activity in the men at the neurological department $(24.1 \pm 2.7 \mathrm{IU} / \mathrm{l})$ was similar to that of the group of conditionally healthy men $(24.5 \pm 0.9 \mathrm{IU} / \mathrm{l})$, well within the range of the standard reference (up to $37.0 \mathrm{IU} / \mathrm{l}$ ).

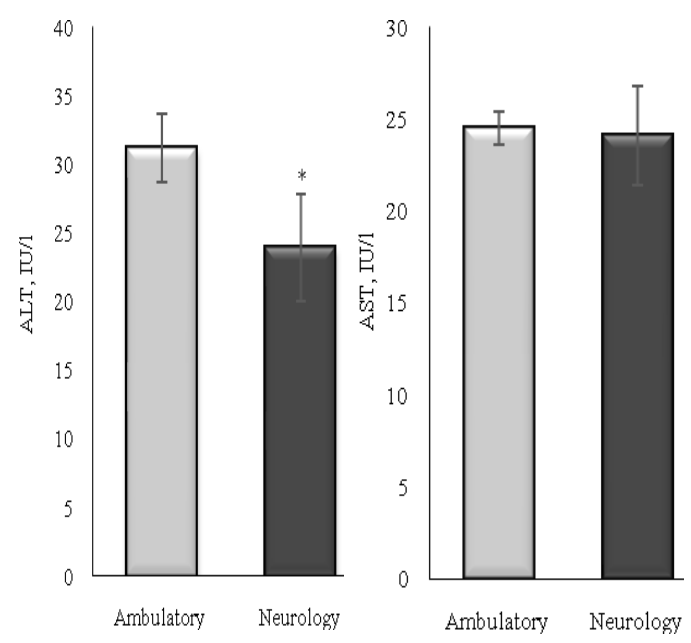

Fig. 2. The activity of alanine aminotransferase (ALT) and aspartate aminotransferase (AST) in the serum of conditionally healthy men and patients of the Department of Neurology:

* $-\mathrm{P}<0.05$ in comparison with the group of conditionally healthy men; $\mathrm{m} \pm \mathrm{SE}, \mathrm{n}=10$

The content of direct and total bilirubin in the men who donated blood for analysis at the ambulatory department and the Department of Neurology was examined. The indicator of direct bilirubin in the group of men from the warzone was $5.1 \pm 0.7 \mu \mathrm{mol} / 1$ (Fig. 3), which falls within the range of reference values (up to $5.4 \mu \mathrm{mol} / \mathrm{l}$ ). However, in comparison with the conditionally healthy men, where the index was $4.0 \pm 0.3 \mu \mathrm{mol} / \mathrm{l}$, a significant increase, by $28.0 \%$, in this indicator was observed in the patients.
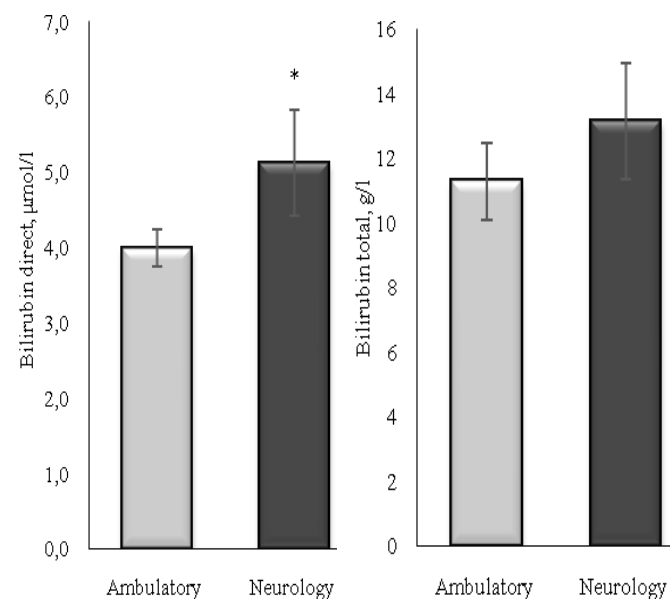

Fig. 3. The content of direct and total bilirubin in the blood of conditionally healthy men and patients at the Department of Neurology: ${ }^{*}-\mathrm{P}<0.05$ a significant difference, compared with the group of conditionally healthy men; $\mathrm{m} \pm \mathrm{SE}, \mathrm{n}=10$

The total bilirubin content, which reflects the total content of direct bilirubin in conjunction with glucuronic acid and the indirect, which is formed by hemoglobin splitting, in the blood of patients in the Department of Neurology was $13.1 \pm 1.8 \mathrm{~g} / \mathrm{l}$. The reference rate of this indicator was up to $21.0 \mathrm{~g} / \mathrm{l}$. The concentration of creatinine in the blood of the men in the Department of Neurology was $74.4 \pm 5.1 \mu \mathrm{mol} / \mathrm{l}$, which did not signifycantly change compared with that of the conditionally healthy men (Fig. 4). The standard reference of this indicator ranges from 55.0 to $110.0 \mu \mathrm{mol} / \mathrm{l}$. The level of urea in the men at the neurology department 
also remained at the same level as that of the conditionally healthy group, amounting to $5.4 \pm 0.5 \mathrm{mmol} / \mathrm{l}$. The acceptable level of urea is $2.5-8.3 \mathrm{mmol} / \mathrm{l}$.

The content of the astrocyte-specific protein, S100b, in the blood of the conditionally healthy men was $0.007 \mu \mathrm{g} / \mathrm{ml}$. For patients at the neurology department, this indicator was $0.011 \mu \mathrm{g} / \mathrm{ml}$, which is $36 \%$ higher than that of the conditionally healthy men (Fig. 5).
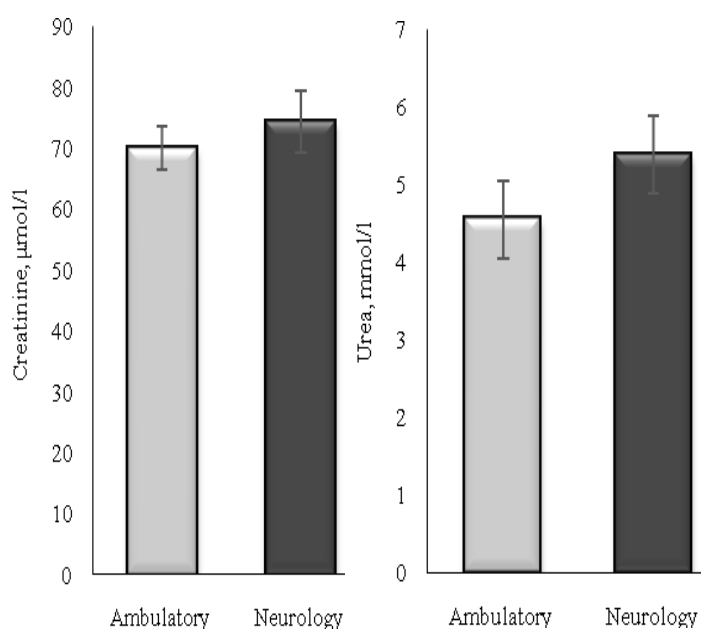

Fig. 4. The concentration of creatinine and urea in the blood of conditionally healthy men and patients at the Department of Neurology: $m \pm S E, n=10$

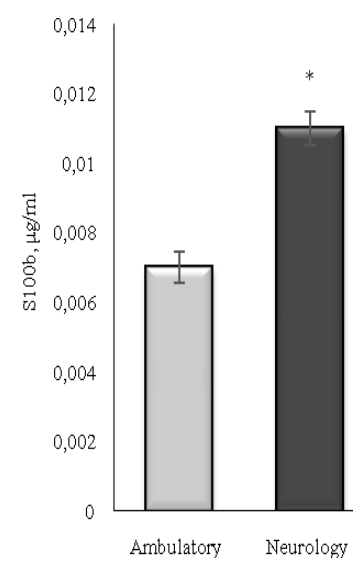

Fig. 5. The content of S100b in the blood of conditionally healthy men and patients at the Department of Neurology: * $-\mathrm{P}<0.001$ a significant difference, compared with the group of conditionally healthy men; $\mathrm{m} \pm \mathrm{SE}, \mathrm{n}=10$

\section{Discussion}

The exchange of proteins represents a crucial stage during total metabolism. In the serum of patients at the Department of Neurology, changes in the total protein level were not observed, compared with the conditionally healthy men, and there were no deviations from the reference data (Hayden et al., 2001; Palmfeldt et al., 2016). No development of hyperglycemia was detected in our study, as evidenced by a stable level of glucose in the blood of the patients. However, in some studies, there is an effect of stress on the development of hyperglycemia (Marik, 2013). Particularly, glucose has been shown to increase in patients with brain trauma (Jeon et al., 2012; Plummer et al., 2016; Rau et al., 2017). The key indicators of protein metabolism in stress are the activity of aminotransferases, as they take part in catabolic and anabolic processes involving amino acids. A 2-3 fold change in the activity of alanine aminotransferase and aspartate aminotransferase in comparison with the norm can indicate the presence of pathologies in violation of the structures and functions of the liver cells and mitochondria under the influence of oxidative stress (Sookoian et al., 2016; Ferrannini et al., 2017). In the blood serum of the men at the Department of Neurology, the activity of alanine aminotransferase was $23.9 \pm 3.9 \mu \mathrm{mol} / \mathrm{l}$, well within the range of the standard reference of $42.0 \mu \mathrm{mol} / \mathrm{l}$, but significant smaller, by $24.0 \%$, compared with that of the conditionally healthy men. A decrease in the activity of aminotransferases is observed during the insufficient intake of protein-containing food or during a decrease in the rate of metabolism as a result of vascular spasm, hypoxia, etc. The total protein in the patients remaining within the norm indicates a disturbance in the liver, where the synthesis of this enzyme occurs (Hayden et al., 2001; Zhang et al., 2014).

Direct bilirubin is formed by destroying hemoglobin in the liver, where it is directed with blood flow and is disintegrated by binding to glucuronic acid. For normal physiological values, it is excreted from the body, but with insufficient oxygen, violations of various levels are observed. Also, bilirubin is one of the important natural antioxidants that inhibit the development of oxidative stress in various pathologies (Oda \& Aizawa, 2013; Haeusler et al., 2016; Nano et al., 2016). But, with increasing concentration, it becomes toxic, which leads to jaundice and damages to the liver and other organs. In the study of the content of direct bilirubin in the men at the Department of Neurology, there was a significant increase, $28.0 \%$, compared with the content in the provisionally healthy men. We can assume that insignificant damages occurred in the liver.

In quantitative terms, proteins form the most important group of macromolecules. Compared with proteins, the proportion of other nitrogen-containing substances in the body is negligible. Therefore, the balance of nitrogen in the body is determined by the metabolism of proteins. The metabolism of nitrogen is generally balanced, that is, the amount of received and allocated nitrogen is approximately equal. Studies of blood urea in the men stationed in the war zone showed no damages compared with the conditionally healthy men. This was confirmed by the indicator of total protein in the serum of the patients, which also did not significantly change compared to that of the group of conditionally healthy men.

Creatinine, as the final product of the disintegration of creatine phosphate, is formed by the spontaneous cyclization of creatine and is the main metabolite of energy metabolism of muscle tissues of the human body. The concentration of creatinine in the blood of patients did not change significantly, remaining within the range of the standard reference, which indicates normal provision of muscles with the necessary energy.

The astrocyte-specific protein, S100b, is a cytosolic protein with a molecular weight of about $21 \mathrm{kDa}$. It can easily penetrate the BBB, making it a sensitive biomarker in assessing the integrity of the BBB (Golmohammadi et al., 2018). Li et al., in their study, showed that military training, which causes a significant level of stress, depression, and anxiety among soldiers, is accompanied by an increased permeability of the BBB (Li et al., 2014). Koh \& Lee also revealed an increase in $\mathrm{S} 100 \mathrm{~b}$ content after exercise. Scientists suggest that the factors influencing the level of S100b may be muscular insufficiency, training levels, and oxidative stress. It is also assumed that an increase in the S100b level depends on the intensity of the exercises and training (Koh \& Lee, 2014). Many studies have shown the dependence of changes in the serum protein S100b level on the level of brain injury (Kleindienst \& Ross Bullock, 2006; Mendes Arent et al., 2014; Kabadi et al., 2015; Roh et al., 2017; Wang, 2018). Additionally, preclinical studies have been presented that demonstrate an increase in protein S100b in animals after modeling stress and depressive behavior (Rajkowska \& Stockmeier, 2013).

The participation of S100 group proteins in the formation of basic forms of congenital behavior and in the mechanisms of memory and learning has been proven experimentally (Hermann et al., 2012; Li et al., 2013; Baptista et al., 2017; Delgado-Moreno et al., 2017). Zhang et al. (2009) reported a deterioration of cognitive characteristics in patients with depression and increased protein S100b, backed by Li et al. (2014), who demonstrated that the $\mathrm{S} 100 \mathrm{~b}$ protein acts as a modulator of the inflamematory response of the hippocampus and plays a key role in reducing cognitive properties. In the blood of the warzone patients in our study, the content of astrocyte-specific protein $\mathrm{S} 100 \mathrm{~b}$ increased significantly by $36.0 \%$, compared with that of the conditionally healthy men, indicating an increase in permeability of the BBB. 
Stress during military operations has, not only obvious immediate consequences, but also remote outcomes that cannot be foreseen (Steele et al., 2017). It can develop into a chronic issue, as a person faces other social and economic problems that exacerbate the effects of stress on the body after the cessation of hostilities (Kirkpatrick et al., 2014). Military monitoring in rehab centers or clinics can provide more focused information on the state of the central nervous system of the patient by determining the level of S100b in the blood.

\section{Conclusions}

Long-term stay in the war zone did not lead to significant changes in the biochemical parameters of the blood. Indicators of total protein, glucose, and end products of metabolism are within the reference range, indicating a balanced protein metabolism. A significant decrease in alanine aminotransferase activity, an increase in the content of direct bilirubin, and increased hemoglobin splitting suggests minor adaptation in the liver. The increased content of the astrocyte-specific protein, S100b, in the blood indicates the development of psychological stress that can increase the permeability of the BBB, which can be used to monitor the state of the central nervous system of soldiers. A more in-depth study is needed to include a wider range of neuro-specific markers of the BBB disturbance.

\section{References}

Baptista, T. S. A., Petersen, L. E., Molina, J. K., de Nardi, T., Wieck, A., do Prado, A., Piovesan, D. M., Keisermann, M., Grassi-Oliveira, R., \& Bauer, M. E. (2017). Autoantibodies against myelin sheath and $S 100 \beta$ are associated with cognitive dysfunction in patients with rheumatoid arthritis. Clinical Rheumatology, 36(9), 1959-1968.

Brindle, R. C., Whittaker, A. C., Bibbey, A., Carroll, D., \& Ginty, A. T. (2017). Exploring the possible mechanisms of blunted cardiac reactivity to acute psychological stress. International Journal of Psychophysiology, 113, 1-7.

Buckner, S. L., Mouser, J. G., Dankel, S. J., Jessee, M. B., Mattocks, K. T., \& Loenneke, J. P. (2017). The general adaptation syndrome: Potential misapplications to resistance exercise. Journal of Science and Medicine in Sport, 20(11), 1015-1017

Carroll, D., Ginty, A. T., Whittaker, A. C., Lovallo, W. R., \& de Rooij, S. R. (2017). The behavioural, cognitive, and neural corollaries of blunted cardiovascular and cortisol reactions to acute psychological stress. Neuroscience and Biobehavioral Reviews, 77, 74-86.

Delgado-Moreno, R., Robles-Pérez, J. J., \& Clemente-Suárez, V. J. (2017). Combat stress decreases memory of warfighters in action. Journal of Medical Systems, 41(8), 124.

Di Battista, A. P., Moes, K. A., Shiu, M. Y., Hutchison, M. G., Churchill, N., Thomas, S. G., \& Rhind, S. G. (2018). High-intensity interval training is associated with alterations in blood biomarkers related to brain injury. Frontiers in Physiology, 9, 1367.

Ferrannini, E., Iervasi, G., Cobb, J., Ndreu, R., \& Nannipieri, M. (2017). Insulin resistance and normal thyroid hormone levels: Prospective study and metabolomic analysis. AJP Endocrinology and Metabolism, 312(5), E429-E436.

Fox, A., Helmer, D., Tseng, C. L., McCarron, K., Satcher, S., \& Osinubi, O. (2018) Autonomic symptoms in gulf war veterans evaluated at the war related illness and injury study center. Military Medicine, 2018, 227.

Gianaros, P. J., \& Wager, T. D. (2015). Brain-body pathways linking psychological stress and physical health. Current Directions in Psychological Science, 24(4), 313-321.

Ginty, A. T., Kraynak, T. E., Fisher, J. P., \& Gianaros, P. J. (2017). Cardiovascular and autonomic reactivity to psychological stress: Neurophysiological substrates and links to cardiovascular disease. Autonomic Neuroscience: Basic and Clinical, 207, 2-9.

Golmohammadi, J., Jahanian-Najafabadi, A., \& Aliomrani, M. (2018). Chronic oral arsenic exposure and its correlation with serum S100B concentration. Biological Trace Element Research, 2018, 1-8.

Gonzalez, L. L., Garrie, K., \& Turner, M. D. (2018). Type 2 diabetes - an autoinflammatory disease driven by metabolic stress. Biochimica et Biophysica Acta - Molecular Basis of Disease, 1864(11), 3805-3823.

Haeusler, R. A., Camastra, S., Nannipieri, M., Astiarraga, B., Castro-Perez, J., Xie, D., Wang, L., Chakravarthy, M., \& Ferrannini, E. (2016). Increased bile acid synthesis and impaired bile acid transport in human obesity. The Journal of Clinical Endocrinology and Metabolism, 101(5), 1935-1944.

Hayden, K., \& van Heyningen, C. (2001). Measurement of total protein is a useful inclusion in liver function test profiles. Clinical Chemistry, 47(4), 793-794.
Jeon, C. Y., Furuya, E. Y., Berman, M. F., \& Larson, E. L. (2012). The role of preoperative and post-operative glucose control in surgical-site infections and mortality. PloS One, 7(9), e45616.

Kabadi, S. V., Stoica, B. A., Zimmer, D. B., Afanador, L., Duffy, K. B., Loane, D. J., \& Faden, A. I. (2015). S100b inhibition reduces behavioral and pathologic changes in experimental traumatic brain injury. Journal of Cerebral Blood Flow and Metabolism, 35(12), 2010-2020.

Kirkpatrick, H. A., \& Heller, G. M. (2014). Post-traumatic stress disorder: Theory and treatment update. The International Journal of Psychiatry in Medicine, 47(4), 337-346.

Kleindienst, A., \& Ross Bullock, M. (2006). A critical analysis of the role of the neurotrophic protein S100B in acute brain injury. Journal of Neurotrauma, 23(8), 1185-1200.

Koh, S. X., \& Lee, J. K. (2014). S100B as a marker for brain damage and bloodbrain barrier disruption following exercise. Sports Medicine, 44(3), 369-385.

Koh, S. X., \& Lee, J. K. (2014). S100B as a marker for brain damage and bloodbrain barrier disruption following exercise. Sports Medicine, 44(3), 369-385.

Kornicka, K., Śmieszek, A., Szłapka-Kosarzewska, J., Irwin Houston, J. M., Roecken, M., \& Marycz, K. (2018). Characterization of apoptosis, autophagy and oxidative stress in pancreatic islets cells and intestinal epithelial cells isolated from equine metabolic syndrome (EMS) horses. International Journal of Molecular Sciences, 19(10), 3068.

Kraynak, T. E., Marsland, A. L., \& Gianaros, P. J. (2018). Neural mechanisms linking emotion with cardiovascular disease. Current Cardiology Reports, 20(12), 128

Li, R. L., Zhang, Z. Z., Peng, M., Wu, Y., Zhang, J. J., Wang, C. Y., \& Wang, Y. L. (2013). Postoperative impairment of cognitive function in old mice: A possible role for neuroinflammation mediated by HMGB1, S100B, and RAGE. Journal of Surgical Research, 185(2), 815-824.

Li, X., Wilder-Smith, C. H., Kan, M. E., Lu, J., Cao, Y., \& Wong, R. K. (2014). Combat-training stress in soldiers increases $\mathrm{S} 100 \mathrm{~B}$, a marker of increased blood-brain-barrier permeability, and induces immune activation. Neuro Endocrinology Letters, 35(1), 58-63.

Marik, P. E., \& Bellomo, R. (2013). Stress hyperglycemia: An essential survival response. Critical Care, 17(2), 305.

Mendes Arent, A., de Souza, L. F., Walz, R., \& Dafre, A. L. (2014). Perspectives on molecular biomarkers of oxidative stress and antioxidant strategies in traumatic brain injury. BioMed Research International, 2014, Article ID 723060 .

Nano, J., Muka, T., Cepeda, M., Voortman, T., Dhana, K., Brahimaj, A., Dehghan, A., \& Franco, O. H. (2016). Association of circulating total bilirubin with the metabolic syndrome and type 2 diabetes: A systematic review and metaanalysis of observational evidence. Diabetes and Metabolism, 42(6), 389-397.

Oda, E., \& Aizawa, Y. (2013). Total bilirubin is inversely associated with metabolic syndrome but not a risk factor for metabolic syndrome in Japanese men and women. Acta Diabetologica, 50(3), 417-422.

Oppenheimer, S., \& Cechetto, D. (2016). The insular cortex and the regulation of cardiac function. Comprehensive Physiology, 6(2), 1081-1133.

Palmfeldt, J., Henningsen, K., Eriksen, S. A., Müller, H. K., \& Wiborg, O. (2016). Protein biomarkers of susceptibility and resilience to stress in a rat model of depression. Molecular and Cellular Neuroscience, 74, 87-95.

Perez de la Hoz, R. A., Swieszkowski, S. P., Cintora, F. M., Aladio, J. M., Papini, C. M., Matsudo, M., \& Scazziota, A. S. (2018). Neuroendocrine system regulatory mechanisms: Acute coronary syndrome and stress hyperglycaemia. European Cardiology Review, 13(1), 29-34

Plummer, M. P., Finnis, M. E., Phillips, L. K., Kar, P., Bihari, S., Biradar, V., Moodie, S., Horowitz, M., Shaw, J. E., \& Deane, A. M. (2016). Stress induced hyperglycemia and the subsequent risk of type 2 diabetes in survivors of critical illness. PLoS One, 11(11), e0165923.

Rajkowska, G., \& Stockmeier, C. A. (2013). Astrocyte pathology in major depressive disorder: Insights from human postmortem brain tissue. Current Drug Targets, 14(11), 1225-1236.

Rau, C. S., Wu, S. C., Chen, Y. C., Chien, P. C., Hsieh, H. Y., Kuo, P. J., \& Hsieh, C. H. (2017). Stress-induced hyperglycemia, but not diabetic hyperglycemia, is associated with higher mortality in patients with isolated moderate and severe traumatic brain injury: Analysis of a propensity score-matched population. International Journal of Environmental Research and Public Health, 14(11), e1340.

Roh, H. T., Cho, S. Y., Yoon, H. G., \& So, W. Y. (2017). Effect of exercise intensity on neurotrophic factors and blood-brain barrier permeability induced by oxidative-nitrosative stress in male college students. International Journal of Sport Nutrition and Exercise Metabolism, 27(3), 239-246.

Siddiqui, A., Madhu, S. V., Sharma, S. B., \& Desai, N. G. (2015). Endocrine stress responses and risk of type 2 diabetes mellitus. The International Journal on the Stress of Biology, 18(5), 498-506.

Sookoian, S., Castaño, G. O., Scian, R., Fernández Gianotti, T., Dopazo, H., Rohr, C., Gaj, G., San Martino, J., Sevic, I., Flichman, D., \& Pirola, C. J. (2016). Serum aminotransferases in nonalcoholic fatty liver disease are a signatore of 
liver metabolic perturbations at the amino acid and Krebs cycle level. The American Journal of Clinical Nutrition, 103(2), 422-434.

Steele, M., Germain, A., \& Campbell, J. S. (2017). Mediation and moderation of the relationship between combat experiences and post-traumatic stress symptoms in active duty military personnel. Military Medicine, 182(5), e1632e1639.

Tahtacı, M., Algın, O., Karakan, T., Yürekli, Ö. T., Alışı, M., Köseoğlu, H., Metin, M. R., Bolat, A. D., Erel, Ö., \& Ersoy, O. (2018). Can pancreatic steatosis affects exocrine functions of pancreas? The Turkish Journal of Gastroenterology, 29(5), 588-594.

Ushakova, G. A., Fomenko, O. Z., \& Pierzynowski, S. G. (2011). Changes in the levels of neurospecific proteins and in behavioral phenomena in rats with hepatic encephalopathy. Neurophysiology, 43(3), 235-238.

Wang, K. K., Yang, Z., Zhu, T., Shi, Y., Rubenstein, R., Tyndall, J. A., \& Manley, G. T. (2018). An update on diagnostic and prognostic biomarkers for traumatic brain injury. Expert Review of Molecular Diagnostics, 18(2), 165-180.
Woodbury-Fariña, M. A. (2014). The importance of glia in dealing with stress. Psychiatric Clinics of North America, 37(4), 679-705.

Yaribeygi, H., Farrokhi, F. R., Butler, A. E., \& Sahebkar, A. (2018). Insulin resistance: Review of the underlying molecular mechanisms. Journal of Cellular Physiology, 2018, e27603.

Zhang, L., Ma, X., Jiang, Z., Zhang, K., Zhang, M., Li, Y., Zhao, X., \& Xiong, H. (2015). Liver enzymes and metabolic syndrome: A large-scale case-control study. Oncotarget, 6(29), 26782-26788.

Zhang, X., Mu, Y., Yan, W., Ba, J., \& Li, H. (2014). Alanine aminotransferase within reference range is associated with metabolic syndrome in middle-aged and elderly Chinese men and women. International Journal of Environmental Research and Public Health, 11(12), 12767-12776.

Zhang, Y., Rothermundt, M., Peters, M., Wiesmann, M., Hoy, L., Arolt, V., Emrich, H. M., \& Dietrich, D. E. (2009). S100B serum levels and word memory processing in remitted major depression as reflected by brain potentials. Neuropsychobiology, 59(3), 172-177. 